\title{
A GIANT UNRUPTURED RIGHT CORONARY SINUS OF VALSALVA ANEURYSM
}

\author{
SEOK-JAE HUH, MD ${ }^{1}$, TAE-HO PARK, MD¹, DONG-YEOL LEE, MD'1, HYOJIN KANG, MD¹, \\ BO-SUNG KIM, MD ${ }^{1}$, YONG-RACK CHO, MD ${ }^{1}$, MOO-HYUN KIM, MD ${ }^{1}$, \\ YOUNG-DAE KIM, MD ${ }^{1}$ AND SUN-MI LEE, MD ${ }^{2}$ \\ 'DEPARTMENTS OF CARDIOLOGY, ${ }^{2}$ FAMILY MEDICINE, DONG-A UNIVERSITY COLLEGE OF MEDICINE, BUSAN, KOREA
}

There have been few case reports on giant sinus of Valsalva aneurysm (SVA). We report a case of a giant unruptured right coronary SVA that was confused with a pericardial cyst by transthoracic echocardiography.

KEY WORDS: Sinus of Valsalva · Aortic aneurysm · Echocardiography.

\section{INTRODUCTION}

Sinus of Valsalva aneurysm (SVA) is a rare cardiac anomaly which may be acquired or congenital. ${ }^{1)}$ SVA is caused by separation of the aortic media of the sinus from the media adjacent to the hinge line of the aortic valve cusp. ${ }^{2}$ Although unruptured SVA usually remains asymptomatic and undetected, with the advent of echocardiography, unruptured SVA is diagnosed more frequently. However, SVA is still usually diagnosed in the setting of rupture. In this report, we describe an asymptomatic unruptured giant SVA, which was confused with a pericardial cyst.

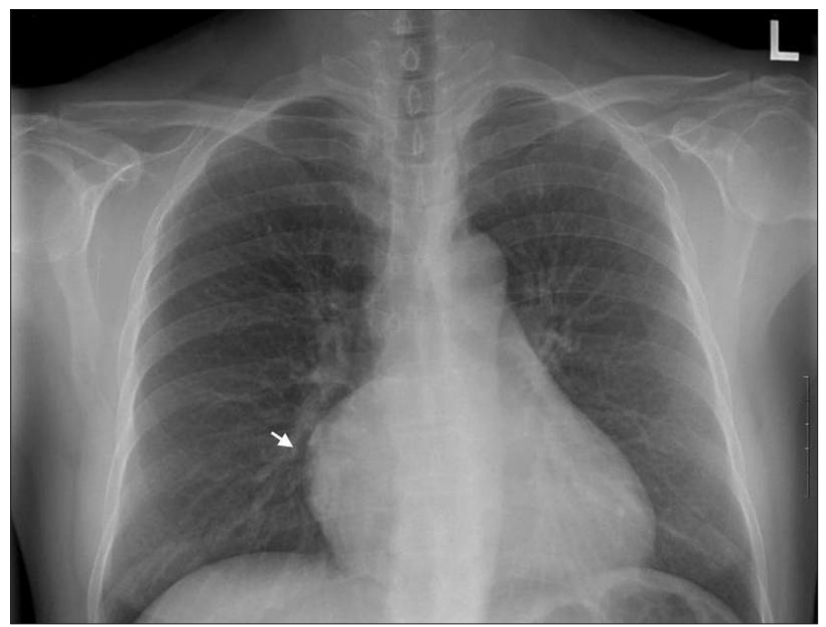

Fig. 1. Chest radiography showed prominent right heart border (arrow) with mild cardiomegaly.

\section{CASE}

A 46-year-old female was referred to our hospital for evaluation of a cardiac mass which was incidentally detected during health assessment. She was asymptomatic. Her blood pressure was 110/70 $\mathrm{mmHg}$ and her pulse rate, 66 beats per minute. Physical examination did not reveal any significant abnormalities and routine laboratory tests were within normal range. The electrocardiogram showed normal sinus rhythm. Chest radiography revealed prominent right heart border with mild cardiomegaly (Fig. 1). Transthoracic echocardiography (TTE) obtained in a parasternal long axis showed aneurysmal structure (arrows) arising from unknown origin (Fig. 2A). Apical 4-chamber view revealed a balloon-like mass (arrows), occupying almost completely the right atrium (Fig. 2B). There was no significant hemodynamic effect of the mass on right atrium (RA) or right ventricle (RV). The round shaped cystic mass was in contact with the tricuspid annulus and RA. The aortic valve was competent. The left ventricular systolic function and wall motion were normal. Initially, the mass was thought to be a pericardial cyst because the cystic mass was superiorly located and extended to the pericardial space. Unruptured coronary SVA was not suspected in first TTE because of its very large size. For confirmation, a thoracic angio-computed tomography (CT) and coronary angiography were performed. Thoracic angio-CT showed a $7 \times 7.5 \mathrm{~cm}$ sized large saccular lesion arising from the right coronary sinus of Valsalva, with the right coronary artery arising from the aneurysm (Fig. 3). After reviewing the TTE images, we recognized the

- Received: October 31, 2011 •Revised: January 5, 2012 •Accepted: February 16, 2012

- Address for Correspondence: Tae-Ho Park, Department of Cardiology, Dong-A University College of Medicine, 26 Daesingongwon-ro, Seo-gu, Busan 602-715,

Korea Tel: +82-51-240-2964, Fax: +82-51-244-1713, E-mail: thpark65@dau.ac.kr

- This is an Open Access article distributed under the terms of the Creative Commons Attribution Non-Commercial License (http://creativecommons.org/licenses/by-nc/3.0) which permits unrestricted non-commercial use, distribution, and reproduction in any medium, provided the original work is properly cited. 

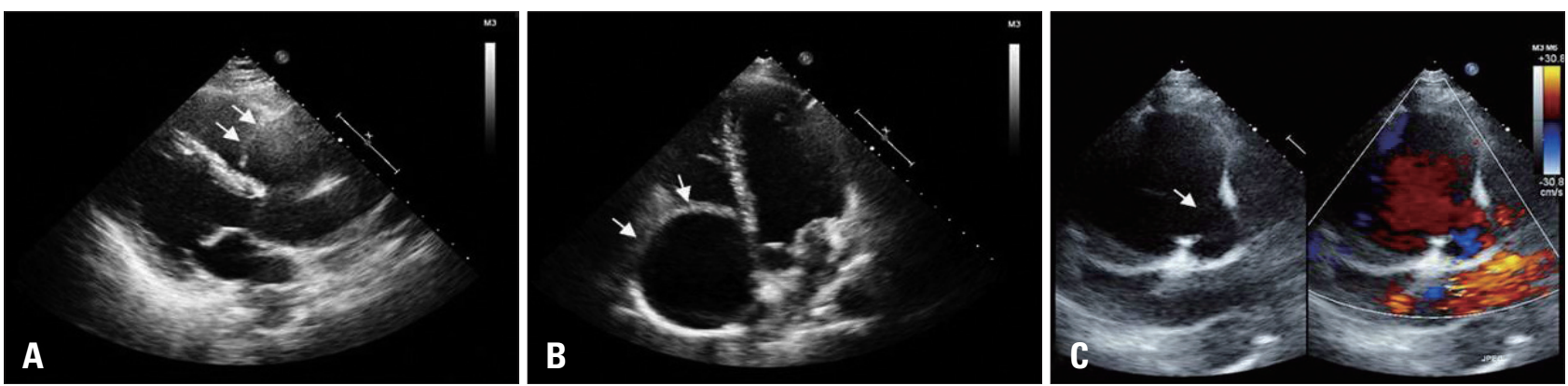

Fig. 2. Transthoracic echocardiography obtained in a parasternal long axis (A) showed aneurysmal structure (arrows) arising from unknown origin. Apical 4-chamber view (B) revealed a balloon-like mass (arrows), occupying almost completely the right atrium. Parasternal short axis view (C) showed that origin (arrow) of aneurysm was visualized from right coronary sinus with blood flow from aortic root to aneurysm.

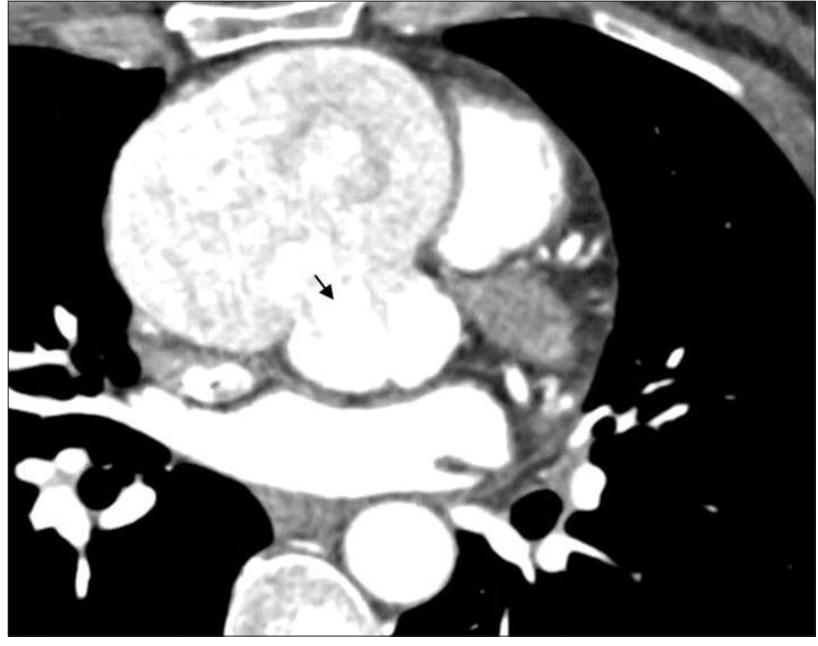

Fig. 3. Thoracic CT showed a large saccular lesion, arising from the right coronary sinus of Valsalva (arrow).

giant cystic mass as a very large sinus of Valsalva aneurysm, which was bulging out from the proximal aortic root (Fig. 2C). Coronary angiography revealed normal coronary arteries and a large unruptured aneurysm in the sinus of Valsalva arising from the right coronary sinus (Fig. 4). The patient underwent elective surgery for SVA repair. Aneurysmectomy and right coronary artery reimplantation were done. Five days after surgery, coronary angiography revealed good anastomosis and normal flow in the right coronary artery. The patient had an uneventful postoperative course, and she was discharged without complications.

\section{DISCUSSION}

The incidence of SVA is 0.14 to $0.96 \%$ of patients undergoing open heart surgery. ${ }^{3)}$ As the aneurysms are frequently silent, their exact prevalence is unknown, however an autopsy study of 8138 individuals suggests a prevalence of $0.09 \%$ in the general population. ${ }^{4)}$ Although most SVAs are congenital in origin, acquired aneurysm is caused by conditions affecting the aortic wall, such as infection, degenerative disease, or thoracic trauma. ${ }^{5(6)}$ Congenital SVAs occur more often in males than female. SVAs are found most often in right coronary sinus, less often in the noncoronary sinus, and least often in left

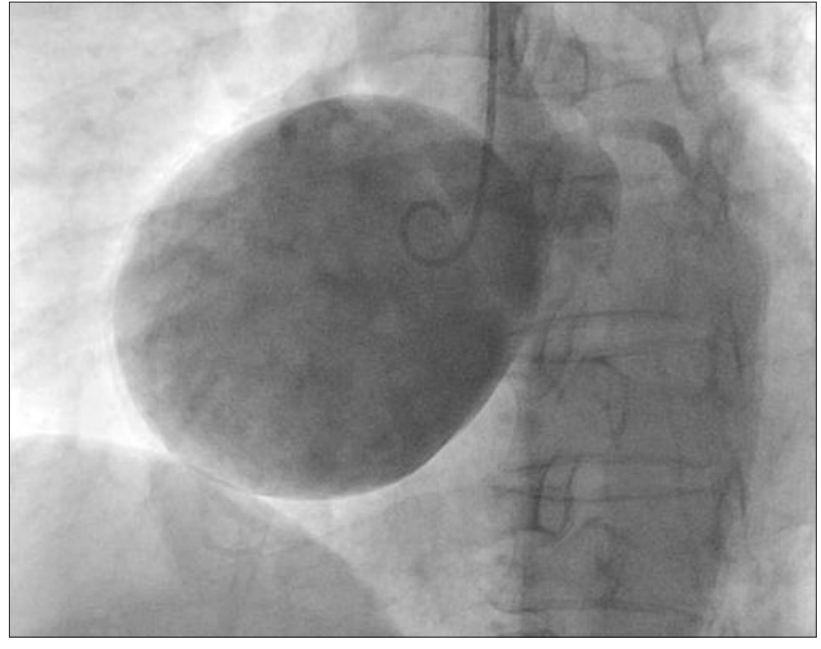

Fig. 4. Coronary angiography revealed a large unruptured aneurysm in the sinus of Valsalva arising from the right coronary sinus.

coronary sinus. ${ }^{7)}$ The size of SVA is variable from $1 \mathrm{~cm}$ to 10 $\mathrm{cm}^{8}{ }^{89)}$ Associated abnormalities include ventricular septal defect (11.6\%), biscuspid aortic valve (16.3\%), and aortic regurgitation (44.2\%). ${ }^{3)}$ Unruptured SVAs are usually asymptomatic. Symptoms develop when the enlarging aneurysm ruptures or compresses adjacent structures. Exertional dsypnea, palpitations, and chest pain have been reported in patients with unruptured aneurysm of the sinus of Valsalva. ${ }^{10)}$ Surgical treatment is advised in the presence of rupture, compression of adjacent structures or in the presence of significant dilatation or aortic regurgitation. The natural history of unruptured aneurysm has not been clearly defined, and no guidelines were provided regarding the timing of surgical intervention. ${ }^{10}$ However, early surgery is usually recommended because surgery produces excellent outcomes in such cases. The operative mortality of SVA is generally low (approximately $1 \%$ ) in patients with noninfected SVAs. ${ }^{11}$

Prior to the advent of noninvasive imaging modalities, SVA was diagnosed by cardiac catheterization. Currently, TTE is the initial imaging technique of choice to delineate ruptured or unruptured SVA. It allows accurate imaging of SVA as well as the presence of associated abnormalities. Parasternal short axis views demonstrate finger-like windsock extending from 
the base of the sinus to right ventricle or right atrium. When the diagnosis of the ruptured SVA is uncertain, coronary angiography, magnetic resonance imaging, or CT can be useful. ${ }^{11}$

In our patient, TTE allowed prompt detection of the huge cystic mass. However, it was difficult to differentiate from a pericardial cyst because the aneurysmal dilatation was seen as balloon-like cystic mass which is not usual finding of SVA, and extended to the pericardial space. SVA was confirmed by cardiac CT. After reviewing the TTE images, origin of aneurysm was visualized from right coronary sinus with blood flow from aortic root to aneurysm. Therefore, for the diagnosis of the SVA, it is important to determine that the aneurysm originates from the aortic sinus. This case could be accurately diagnosed by TTE, if we had used multiple views including parasternal short axis view of aortic root. This is a rare case of a giant right coronary SVA, confused with pericardial cyst.

\section{REFERENCES}

1. Feldman DN, Roman MJ. Aneurysms of the sinuses of Valsalva. Cardiology 2006;106:73-81.

2. Edwards JE, Burchell HB. The pathological anatomy of deficiencies between the aortic root and the heart, including aortic sinus aneurysms. Tho$\operatorname{rax} 1957 ; 12: 125-39$
3. Takach TJ, Reul GJ, Duncan JM, Cooley DA, Livesay JJ, Ott DA, Frazier $\mathrm{OH}$. Sinus of Valsalva aneurysm or fistula: management and outcome. Ann Thorac Surg 1999;68:1573-7.

4. Smith WA. Aneurysm of the sinus of Valsalva, with report of 2 cases. JAMA 1914;62:1878-80.

5. Batiste C, Bansal RC, Razzouk AJ. Echocardiographic features of an unruptured mycotic aneurysm of the right aortic sinus of Valsalva. J Am Soc Echocardiogr 2004;17:474-7.

6. Greiss I, Ugolini P, Joyal M, Bouchard D, Mercier LA. Ruptured aneurysm of the left sinus of Valsalva discovered 41 years after a decelerational injury. J Am Soc Echocardiogr 2004;17:906-9.

7. Fishbein MC, Obma R, Roberts WC. Unruptured sinus of Valsalva aneurysm. Am J Cardiol 1975;35:918-22.

8. Sen T, Guray Y, Hajro E, Demirkan BM. Giant unruptured noncoronary sinus of Valsalva aneurysm with ascending aorta dissection. Eur J Cardiothorac Surg 2009;36:187.

9. Viktorsson TV, Arnorsson T, Sigurdsson MI, Sverrisson JT, Gudbjartsson T. A giant unruptured aneurysm of the sinus of Valsalva together with ectasia of the left coronary artery. Ann Thorac Surg 2011;92:354-6.

10. Liau CS, Chu IT, Ho FM. Unruptured congenital aneurysm of the sinus of Valsalva presenting with pulmonary stenosis. Catheter Cardiovasc Interv 1999;46:210-3.

11. Ott DA. Aneurysm of the sinus of valsalva. Semin Thorac Cardiovasc Surg Pediatr Card Surg Anпu 2006:165-76. 